\title{
Angiotensin-Converting Enzyme I/D Polymorphism in Behçet's Disease
}

\author{
Sebahat Turgut ${ }^{a, c}$ Günfer Turgut ${ }^{a, c}$ Erol Ömer Atalay ${ }^{b, c}$ Ayfer Atalay $^{\text {b,c }}$ \\ Departments of a Physiology and ${ }^{b}$ Biophysics, Faculty of Medicine, Pamukkale University, and \\ ${ }^{c}$ Pamukkale University Research Center for Genetic Engineering and Biotechnology, Denizli, Turkey
}

\section{Key Words}

Angiotensin-converting enzyme $\cdot$ Angiotensinconverting enzyme I/D polymorphism - Behçet's disease

\begin{abstract}
Objective: To investigate a potential relationship between I/D polymorphism within intron 16 of the angiotensin-converting enzyme (ACE) gene located on human chromosome 17 and Behçet's disease. Materials and Methods: Genomic DNA was obtained from 35 Turkish patients diagnosed with Behçet's disease according to the International Study Group criteria and 150 healthy individuals. Polymerase chain reaction was used to detect the presence of I and $D$ (insertion and deletion) alleles in intron 16 of the ACE gene in these DNA samples. Results: We found differences in ACE I/D polymorphism between Behçet's disease and healthy controls $\left(\chi^{2}=4.61\right.$, d.f. $=1, p=0.044)$. In Behçet's disease patients, the $D$ allele frequency was $84.3 \%$ and I allele frequency $15.7 \%$. Conclusion: An association between Behçet's disease and ACE polymorphism may provide a useful basis for future molecular studies and therapeutic approaches in this complex disease.
\end{abstract}

\section{Introduction}

Behçet's disease (BD) is a refractory, systemic inflammatory disease characterized by four main symptoms: oral aphthous ulcers, ocular lesions, skin lesions, and genital ulcers. It is occasionally responsible for inflammation in tissue and organs throughout the body including the vascular system, central nervous system, gastrointestinal tract, lungs, kidneys, and joints [1]. The etiology of $\mathrm{BD}$ is unknown and BD is seen most frequently among Turkish, Israeli and Japanese populations. It has been claimed that immunologic abnormalities triggered by microbial agents or environmental factors in genetically susceptible individuals play an important role in the development of this disease [2]. Vascular injuries, hyperfunction of neutrophils, and autoimmune responses are also significant characteristics of BD [3], but the clinical features of BD differ from those of classic autoimmune diseases [4]. It has been shown that in $\mathrm{BD}$ endothelial damage could occur as a result of different immunological abnormalities [5].

Angiotensin-converting enzyme (ACE) has been identified as a membrane-bound enzyme in several types of cells, including vascular endothelial cells, various absorptive epithelial cells, neurons, macrophages, and $\mathrm{T}$ lymphocytes. It is also present in a circulating form, produced

\section{KARGER}

Fax +4161306 1234 E-Mail karger@karger.ch www.karger.com 


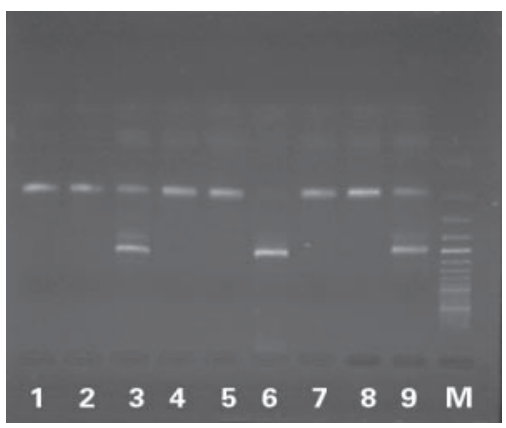

Fig. 1. Electrophoretic analysis of PCR products demonstrating genetic (I/D) polymorphism of ACE in BD: DD (lanes 1, 2, 4, 5, 7, 8), ID (lanes 3, 9), II (lanes 6), M (marker, 100-bp ladder).

by vascular endothelial cells, in biological fluids such as plasma. The levels of tissue and circulating ACE activities are under tight genetic control [6]. The ACE gene is located on chromosome 17 and shows polymorphism that is characterized by the presence of a 287 -base pair alu repeat within intron 16 [7]. The presence of the extra fragment is associated with lower circulating and tissue ACE activity, and this variant of the ACE gene is termed the insertion (or I) allele. The absence of this fragment (deletion or D allele) is associated with relatively higher ACE activity [8]. The allelic frequency of the ACE gene varies among different racial and ethnic groups $[9,10]$.

This study aimed to evaluate the possible role of the ACE I/D polymorphism in BD.

\section{Subjects and Methods}

Genomic DNA from 35 Turkish patients (23 male, 12 female), diagnosed with BD according to the International Study Group criteria, and 150 healthy individuals ( 97 male, 53 female) was prepared from peripheral blood samples by a standard phenol/chloroform extraction method [11]. Polymerase chain reaction (PCR) was used to detect the presence of I and D alleles in intron 16 of the ACE gene according to the method described by Rigat et al. [8] usingan upstreamprimer 5'-CTGGAGACCACTCCCATCCTTTCT$3^{\prime}$ and downstream primer 5'-GATGTGGCCATCACATTCGTCAGAT-3'. Amplification was performed for 35 cycles with denaturation, extension and annealing temperatures of 94, 60 and $72^{\circ} \mathrm{C}$, respectively. Amplified fragments (490 bp for the I allele and $190 \mathrm{bp}$ for the $\mathrm{D}$ allele) were separated by $2 \%$ agarose gel electrophoresis and identified using the UVI Gel Documentation system.

Conformity with the Hardy-Weinberg equilibrium for genotype distribution was estimated by $\chi^{2}$ test. A value of $p<0.05$ was considered statistically significant. All statistical analyses were carried out using the SPSS 10.0 computer program (Statistical Package for Social Sciences, SPSS Inc.).

\section{Results}

Electrophoretic identification of the alleles according to their PCR product length is shown in figure 1 and genotype and allele frequencies are given in table 1. In BD patients the D allele was seen in 59 alleles out of 70 chromosomes corresponding to an allele distribution of $84.3 \%$, and the I allele in 11 chromosomes (15.7\%). Differences in DD, ID and II genotypes did not show statistical significance between the BD patients and controls. However, D and I allele frequencies showed sta-

Table 1. Distribution of ACE I/D polymorphism in BD and normal subjects

\begin{tabular}{|c|c|c|c|c|c|c|c|c|c|c|}
\hline \multirow[t]{3}{*}{ Subjects } & \multicolumn{6}{|c|}{ ACE genotypes } & \multicolumn{4}{|c|}{ ACE alleles } \\
\hline & \multicolumn{2}{|c|}{ DD } & \multicolumn{2}{|l|}{ ID } & \multicolumn{2}{|l|}{ II } & \multicolumn{2}{|l|}{$\mathrm{D}$} & \multicolumn{2}{|l|}{ I } \\
\hline & $\mathrm{n}$ & $\%$ & $\mathrm{n}$ & $\%$ & $\mathrm{n}$ & $\%$ & $\mathrm{n}$ & $\%$ & $\mathrm{n}$ & $\%$ \\
\hline Controls $(n=150)$ & 87 & 58 & 44 & 29.3 & 19 & 12.7 & 218 & 72.7 & 82 & 27.3 \\
\hline \multirow[t]{2}{*}{$\mathrm{BD}(\mathrm{n}=35)$} & 26 & 74.3 & 7 & 20 & 2 & 5.7 & 59 & 84.3 & 11 & 15.7 \\
\hline & \multicolumn{6}{|c|}{$\chi^{2}=3.19$, d.f. $=1, p=0.074$} & \multicolumn{4}{|c|}{$\chi^{2}=4.61$, d.f. $=1, p=0.044$} \\
\hline
\end{tabular}


tistically significant $(\mathrm{p}<0.05)$ differences between the BD patients and controls. We did not observe any relationship of D and I allele frequency and gender in BD patients.

\section{Discussion}

$\mathrm{BD}$ is a systemic inflammatory disorder with unknown pathogenesis. Although the most common features are recurrent oral and/or genital ulcerations, many other systems such as the gastrointestinal tract, the central nervous system, and the skin and blood vessels may be affected. The prevalence and incidence of the condition and its constituent manifestations show marked variability among different populations [12]. The vascular injuries are superimposed on a hypercoagulability that is also characteristic of $\mathrm{BD}$ and which may be due in part to activated endothelial cells and activated platelets [3].

Extensive expression of adhesion molecules on vascular endothelial cells of BD patients was reported recently, suggesting that adhesion molecules might play an important role in vasculitis. In addition, plasma endothelin-1 (ET-1) concentrations were found to be significantly increased in patients with active BD. Elevated ET-1 is the direct result of its increased synthesis from injured vascular endothelial cells. Plasma ET-1 levels correlate with disease activity. These findings indicate that ET-1 may play an important role in the development or progression of vasculitis [5].

ACE in mononuclear cells may participate in local production or degradation of regulatory peptides (for example, at the site of inflammation reactions). Some naturally occurring inflammatory peptides, such as bradykinin and substance $\mathrm{P}$, are partially inactivated by ACE. The renin-angiotensin system (RAS) itself is likely to influence cytokine synthesis; interleukin-1-induced cytokine synthesis was increased by approximately $20 \%$ in the presence of angiotensin II. Like ACE, angiotensinogen gene expression is subject to tissue-specific hormonal and developmental controls. Endocrine RAS activities are associated with the regulation of vascular tonus and cardiac function in the body, while autocrine RAS activities contribute to inflammation reactions in tissues [6].

ACE is involved in the conversion of angiotensin I to angiotensin II through its metalloproteinase enzymatic activity and plays a major role in RAS and kallikrein-kininogen systems. Angiotensin II increases vascular smooth muscle cell contraction and affects smooth muscle proliferation, monocyte adhesion, and platelet adhesion and aggregation [13].
ACE is attractive as a candidate to play a role in the development of vascular pathological states. Evidence suggests that the DD genotype increases susceptibility for coronary heart disease, myocardial infarction, and both diabetic and nondiabetic renal disease [14]. This enzyme plays an integral role in the regulatory system responsible for endothelial control and vascular tone, systems that are commonly affected in lupus patients [13]. In addition, it has been shown that the circulating level of the ACE is approximately twofold higher in individuals homozygous for the ACE deletion (D) allele [8]. An association of the D genotype with chronic inflammation in the bronchiole in asthma has been indicated [6]. In tissues, the production of angiotensin I is higher than in plasma ( $80 \mathrm{vs.} 20 \%$ ). Recent studies have shown that control of RAS in tissues is independent of levels in circulation. ACE expression is closely regulated by dexamethasone, because glucocorticoid-responsive elements are located in the ACE promoter. These studies indicate multifactorial control of ACE expression in tissues [15].

In this study we investigated the relationship between ACE polymorphism and BD. According to these preliminary observations, BD patients living in Denizli province of Turkey show a D allele frequency that is greater than that in the general population, representing a statistically significant difference $\left(\chi^{2}=4.61\right.$, d.f. $\left.=1, p=0.044\right)$. Since the ACE genes are functional in physiological control, the frequency of the $\mathrm{D}$ allele, with concomitant high levels of ACE production might contribute to the overall pathogenesis of the disease. We postulate that the increased expression of ACE might be influenced by the D allele in nonendothelial tissues under pathologic conditions, given the effect of $\mathrm{D}$ alleles on inducible expression of angiotensin II during the progress of tissue inflammation [16].

\section{Conclusion}

Our results indicate that in patients with $\mathrm{BD}, \mathrm{D}$ alleles of the ACE gene are present at a higher frequency than in the normal Turkish population. Although the number of patients in this initial study was limited, we believe that the ACE D allele may represent a significant factor in BD. We recommend that other factors, such as angiotensin II gene polymorphisms and RAS components that may contribute to inflammation in $\mathrm{BD}$, should also be investigated. This approach should aid progress in the characterization and therapy of this disease. 


\section{Acknowledgments}

We are thankful to Research Assistants Sanem Y1ldız and Anzel Bahadır for their valuable technical assistance. Authors are also thankful to Dr. Cem Yıldırım and Dr. Veli Çobankara for the BD patient identifications. Control and patient DNA samples were obtained from Pamukkale University, Research Center for Genetic
Engineering and Biotechnology Genome Bank (PAMGEN). This study was supported by Pamukkale University Research Fund (Project No. 2000TPF/FAD01 and 2001TPF020), TÜBITAK (Scientific and Research Council of Turkey, Project No. SBAG 2388) and Turkish Government State Planning Department Project (Project No. 2001K121120).

\section{References}

1 Mizuki N, Ohno S: Immunogenetic studies of Behçet's disease. Rev Rhum Engl Ed 1996;63: 520-527.

-2 Gül A, Uyar FA, Inanç M, Ocal L, Barrett JH, Aral O, Konice M, Saruhan-Direskeneli G: A weak association of HLA-B*2702 with Behçet's disease. Genes Immun 2002;3:368-372.

-3 Sakane T, Takeno M, Suzuki N, Inaba G: Behçet's disease. N Engl J Med 1999;341: 1284-1291.

4 Yazıcı H: The place of Behçet's disease among the autoimmune diseases. Int Rev Immunol 1997;14:1-10.

5 Önder M, Gürer MA: The multiple faces of Behçet's disease and its aetiological factors. J Eur Acad Dermatol Venereol 2001;15:126136.

-6 Holla L, Vasku A, Znojil V, Siskova L, Vacha $\mathrm{J}$ : Association of 3 gene polymorphisms with atopic disease. J Allergy Clin Immunol 1999; 103:702-708.
Prasad A, Narayanan S, Waclawiw MA, Epstein N, Quyyumi AA: The insertion/deletion polymorphism of the angiotensin-converting enzyme gene determines coronary vascular tone and nitric oxide activity. J Am Coll Cardiol 2000;36:1579-1586.

8 Rigat B, Hubert C, Alhenc-Gelas F, Cambien F, Corvol P, Soubrier F: An insertion/deletion polymorphism in the angiotensin-1-converting enzyme gene accounting for half the variance of serum enzyme levels. J Clin Invest 1990;86: 1343-1346.

-9 Mattu RK, Needham E, Galton DJ, Frangos E, Clark AJ, Caulfield M: A DNA variant at the angiotensin-converting enzyme gene locus associates with coronary artery disease in the Caerphilly heart study. Circulation 1995;91: 270-274.

10 Wang XL, McCredie RM, Wilcken DEL: Genotype distribution of angiotensin-converting enzyme polymorphism in Australian healthy and coronary populations and relevance to myocardial infarction and coronary artery disease. Arterioscler Thromb Vasc Biol 1996;16: 115-119.
11 Ponez M, Solowiejczky D, Harpel B, Mory Y, Schwartz E, Surrey S: Construction of human gene libraries from small amounts of peripheral blood. Hemoglobin 1982;6:27-36.

12 Barnes CG, Yazici H: Behcet's syndrome. Rheumatology (Oxford) 1999;38:1171-1174.

13 Kaufman KM, Kelly J, Gray-McGuire C, Asundi N, Yu H, Reid J, Baird T, Hutchings D, Bruner G, Scofield RH, Moser K, Harley JB: Linkage analysis of angiotensin-converting enzyme (ACE) insertion/deletion polymorphism and systemic lupus erythematosus. Mol Cell Endocrinol 2001;177:81-85.

14 Kennon B, Petrie JR, Small, M, Connell JM: Angiotensin-converting enzyme gene and diabetes mellitus. Diabet Med 1999;16:448-458.

15 Coulet F, Gonzalez W, Boixel C, Meilhac O, Pueyo ME, Michel JB: Endothelium-independent conversion of angiotensin I by vascular smooth muscle cells. Cell Tissue Res 2001;303: 227-234.

16 Ardaillou R, Michel JB: The relative roles of circulating and tissue renin-angiotensin systems. Nephrol Dial Transplant 1999;14:283286. 